\title{
Genç Erişkinlerde Fiziksel Aktivite Düzeyi ile Vücut Kompozisyonu İlişkisi: Pilot Çalışma
}

\author{
The Relationship between Body Composition and Physical Activity Level in the Young \\ Adults: Pilot Study
}

\author{
Aysel YILDIZ ${ }^{1}$, Devrim TARAKCI ${ }^{2}$, Fatma KARANTAY MUTLUAY $^{3}$
}

\begin{abstract}
ÖZET Amaç: Genç erişkinlerde fiziksel aktivite düzeyi ile vücut kompozisyonu ve cinsiyet arasındaki ilişkiyi araştırmaktı. Materyal ve Metod: Son 6 ay içinde kardiyopulmoner, ortopedik, romatizmal ya da metabolik hastalık hikayesi olmayan 62 öğrenci çalıșmada yer aldı. Öğrencilerin demografik ve fiziksel özellikleri kaydedildi. Fiziksel aktivite düzeyi FIT Skoru ile belirlendi, vücut kompozisyonunu değerlendirmesinde Beden Kütle İndeksi ile skinfold kaliper ölçümlerinden elde edilen değerler kullanılarak hesaplanan vücut yağ oranı ve ideal vücut ağırlı̆ı̆ kullanıldı. Bulgular: Katılımcıların fiziksel aktivite ortalaması 27,08 $\pm 18,74$ olarak bulundu. Fiziksel aktivite seviyesi çok iyi olan öğrenciye rastlanmadı. Kızların fiziksel aktiviteleri $(26,53 \pm 19,73)$ ve erkeklerin fiziksel aktivite $(27 \pm 18,55)$ ortalamaları arasında fark bulunmadı $(\mathrm{p}=0,936)$. Erkeklerin beden kütle indeksi $\left(24,92 \pm 3,15 \mathrm{~kg} / \mathrm{m}^{2}\right)$ kızlardan $\left(21,23 \pm 3,18 \mathrm{~kg} / \mathrm{m}^{2}\right)$ yüksekti $(\mathrm{p}=0,004)$. Kızların vücut yağ oranı $(\% 22,74 \pm 6,93)$ erkeklerin vücut yağ oranından $(\% 16,60 \pm 5,46)$ yüksekti $(\mathrm{p}=0,003)$. Her iki cinsiyet arasında fazla kilo yüzdesi bakımından fark yoktu (kızlar:0,05 $\pm 0,12$ erkekler:0,06 $\pm 0,11, \mathrm{p}=0,804)$. Korelasyon analizinde kızlarda fiziksel aktivite ve beden kütle indeksi arasında anlamlı ilişki saptanmadı $(\mathrm{p}=0,055)$ ancak erkeklerde fiziksel aktivite ile beden kütle indeksi $\left(\mathrm{r}_{\mathrm{s}}=0,662, \mathrm{p}=0,007\right)$, vücut yağ oranı $\left(\mathrm{r}_{\mathrm{s}}=0,602, \mathrm{p}=0,018\right)$, ideal vücut ağırlığı $\left(r_{s}=0,544, p=0,036\right)$ ve fazla kilo yüzdesi arasında pozitif yönde anlamlı ilişki saptandı $\left(r_{s}=0,560\right.$, $\mathrm{p}=0,030$ ).Sonuç: Katılımcıların fiziksel aktivite düzeylerinin düşük seviyede olup beden kütle indekslerinin ve yağ oranlarının normal sınırlar içerisinde olması çalışmanın genç popülasyonda yapılmış olması ile açıklanabilir. Gençlerin vücut kompozisyonlarının sağlıklı olması sevindiricidir ancak ileride inaktiviteye bağlı olarak ortaya çıkabilecek sorunları önlemek açısından fiziksel aktiviteye daha fazla teşvik edilmesi gerektiği düşünülmektedir. Anahtar kelimeler: Fiziksel aktivite, genç erişkin, vücut kompozisyonu
\end{abstract}

\begin{abstract}
Aim: The aim of this study was to investigate the relationship between body composition and physical activity level in the young adults. Materials and Methods: 62 student with no history of cardiopulmonary, orthopedic, rheumatic or metabolic diseas in last 6 months were participate in the study. Their demographic and physical characteristics were recorded. The physical activity levels were determined by FIT score. Body mass index and fat tissue measurements with skinfold caliper, body fat percentage, and ideal weight were calculated by special formulas. Results: Participant's FIT score was found 27,08 $\pm 18,74$. There was no perfect FIT score. There wasn't statistically significant difference between males' $(27 \pm 18,55)$ and females' $(27,08 \pm 18,74)$ physical activity levels $(\mathrm{p}=0,936)$. The males' body mass index $\left(24,92 \pm 3,15 \mathrm{~kg} / \mathrm{m}^{2}\right)$ were higher than the females's $\left(21,23 \pm 3,18 \mathrm{~kg} / \mathrm{m}^{2}\right)(\mathrm{p}=0,004)$. The females' body fat percentage $(22,74 \pm 6,93 \%)$ was found higher than the males' $(16,60 \pm 5,46 \%)(\mathrm{p}=0,003)$. There wasn't statistically significant difference between males' percentage of overweight $(0,06 \pm 0,11)$ and females' percentage of overweight $(0,05 \pm 0,12),(p=0,804)$ There wasn't significant relation between physical activity and body mass index in females $(\mathrm{p}=0,055)$ but there were significantly positive correlation between physical activity, body mass index $\left(\mathrm{r}_{\mathrm{s}}=0,662, \mathrm{p}=0,007\right)$, the ideal body weight $\left(\mathrm{r}_{\mathrm{s}}=0,544, \mathrm{p}=0,036\right)$, body fat percentage $\left(\mathrm{r}_{\mathrm{s}}=0,602, \mathrm{p}=0,018\right)$ and overweight percentage $\left(\mathrm{r}_{\mathrm{s}}=0,602\right.$, $\mathrm{p}=0,018$ ) in males. Conclusion: The low physical activity level, however, their normal body mass index can be explained by conducting the experiment coming young population. Young adults' body compositions are healtly that is something good. However, they should be encouraged to engage with more physical activity.
\end{abstract}

Key words: Physical activity, young adult, body composition

Geliş Tarihi/Received:08.05.2015 /Kabul Tarihi/Accepted:01.08.2015

${ }^{1}$ Yrd. Doç. Dr., İstanbul Medipol Üniversitesi, Sağlık Bilimleri Fakültesi, Fizyoterapi ve Rehabilitasyon Bölümü.

e-mail:ayselyildiz@medipol.edu.tr

${ }^{2}$ Yrd. Doç. Dr. İstanbul Medipol Üniversitesi, Sağlık Bilimleri Fakültesi, Fizyoterapi ve Rehabilitasyon Bölümü e-mail: dtarakci@medipol.edu.tr.

${ }^{3}$ Doç. Dr., İstanbul Medipol Üniversitesi, Sağlık Bilimleri Fakültesi, Fizyoterapi ve Rehabilitasyon Bölümü, e-mail:fmutluay@medipol.edu.tr

Yazışma adresi/ correspondence: Ayşe Yıldız, e-mail:ayselyildiz@medipol.edu.tr, İstanbul Medipol Üniversitesi Kavacık Kampüsü C Blok, Sağlık Bilimleri Fakültesi, Fizyoterapi ve Rehabilitasyon Bölümü, Beykoz 


\section{Giriş}

Fiziksel inaktivite sağlığın (fiziksel uygunluğun) iyi bir şekilde sürdürülebilmesi için "gerekenden daha düşük" fiziksel aktivite düzeyi olarak tanımlanmaktadır. Dünya Sağlik Örgütü (DSÖ), fiziksel inaktiviteyi global mortalite için dördüncü büyük risk faktörü ve 21. Yüzyılın en büyük halk sağlığ problemi olarak bildirmektedir. ${ }^{1}$

Fiziksel inaktivite, DSÖ'nce "Bulaşıcı Olmayan Hastalıklar (BOH)" olarak tanımlanan ve bireyin yaşam kalitesi kadar sağlık bakım maliyetine de negatif etkileri olan diyabet, kardiyovasküler problemler, kanser ve kronik akciğer hastalıklarına zemin hazırlayan temel faktörlerden biridir. ${ }^{2,3}$

Fiziksel uygunluk, genel sağlı̆̆ın bir göstergesi olarak, fiziksel eforlara uygun cevap verebilme kapasitesidir. Fiziksel uygunluğu ölçmede kullanılan parametrelerden biri olan vücut kompozisyonu Beden Kütle İndeksi (BKİ) ve Vücut Yağ Oranı (VYO) hesaplamaları ile değerlendirilir. $\mathrm{Bu}$ ölçümler, obezite başta olmak üzere klinik bilimler, spor bilimleri ve halk sağlığı ile ilgili alanlarda bireylerin sağlık durumu hakkında bilgi edinmek amacı ile kullanılmaktadır. ${ }^{4-7}$

Fiziksel aktivite, bedenin enerji dengesini düzenleyerek kilo kontrolünü sağlamakta ve vücut kompozisyonunu belirlemektedir. Fiziksel aktivite düzeyinin doğru ve güvenilir yöntemlerle ölçümü için doğrudan ve dolaylı yöntemler kullanılabilmektedir. ${ }^{8,9}$

$\mathrm{Bu}$ çalışmanın amacı, sağlıklı genç erişkinlerde fiziksel aktivite düzeyini belirlemek ve vücut kompozisyonu ile ilişkisini incelemek, aynı zamanda cinsiyetler arası farklılıkları araştırmaktır.

\section{Materyal ve Metod \\ Katılımcılar}

Gönüllülük prensibine göre çalışmaya katılmayı kabul eden, bilinen sağlık problemi olmayan 21-25 yaş arası üniversite öğrencileri araştırmada yer aldı. Katılımcılar çalışmanın içeriği hakkında bilgilendirilerek onamları alınd1. Fiziksel aktiviteyi engelleyecek konjenital problemi olanlar ile son 6 ay içinde kardiyopulmoner, ortopedik, romatizmal ya da metabolik hastalık hikayesi olan bireyler çalışma dişında tutuldu.

\section{Çalışma prosedürü}

Katılımcıların yaş, cinsiyet, boy ve kilo, kas iskelet ve kronik hastalık varlığ 1 sorguland1. Alınma kriterlerine uymayan 5 gönüllü çalışma dışı bırakıldı.

\section{Fiziksel Aktivite düzeyi}

Fiziksel aktivite düzeyi, yapılan aktivitenin şiddeti, süresi ve frekansı ile hesaplanabilmektedir. Çalışmamızda katılımciların fiziksel aktivite düzeyi Fiziksel aktivite indeksi (FIT skoru) ile değerlendirildi. ${ }^{10}$ Fiziksel aktivite skoru Kasari FIT Skoru ile aktivitenin yapılma sıklığı (frequency), şiddeti (intensity) ve süresinin (time) çarpımı ile elde edildi (Tablo 1). FIT puanına göre fiziksel aktivite düzeyi 0-20 arası sedanter, 21-40 arası zayıf, 41-60 arası normal, 61-80 puan arası iyi ve 81-100 arası çok iyi olarak yorumlanmaktadır.

\section{Vücut kompozisyonu}

Vücut kompozisyonu, fiziksel uygunluğun en önemli göstergelerinden birisi olup vücuttaki kas, kemik ve yağ oranlarını ifade etmektedir. Yağlı ve yağsız vücut kütlesinin toplamı aynı zamanda vücut ağırlığını oluşturmaktadır. Vücudun toplam yağ oranının yarısı deri altı yağ depolarında biriktiği için skinfold kaliper ile derialtı yăg ölçümü yapılarak toplam yağ miktarı klinik olarak ölçülebilir.

Vücut kompozisyonu için stadiometre ile katılımcıların boy ve kiloları ölçüldü; BKI hesapland1, sonrasinda skinfold kaliper ile yăg dokusu ölçümleri yapıldı. Skinfold ölçümlerinden elde edilen değerlerden vücut yă̆ yüzdeleri ve ideal vücut ağırlıkları hesaplanarak kaydedildi.

BKİ, kilogram cinsinden vücut ağırlığının, metre cinsinden boy uzunluğu karesine oranı alınarak hesapland1. BKI $\leq 18.5 \mathrm{~kg} / \mathrm{m}^{2}$ 
zayif, $18.6-24.9 \mathrm{~kg} / \mathrm{m}^{2}$ aras1 normal, 25.0 $29.9 \mathrm{~kg} / \mathrm{m}^{2}$ aras1 fazla kilolu, $\geq 30.0 \mathrm{~kg} / \mathrm{m}^{2}$ obez olarak tanımland.

Skinfold kaliper (Holtain) ölçümleri karm (abdomen), kol (triceps), ve uyluk bölgelerinden yapılarak ikişer ölçümün ortalaması alındı. Ölçüm için deri ve deri altı yağı baş ve işaret parmağıyla tutularak kastan uzaklaştırıldı. Skinfold aletinin kolları deri kıvrımına yerleştirildi ve kalibre milimetre cinsinden okundu. Karın ölçümü göbeğin $2 \mathrm{~cm}$ yan tarafindan; kol ölçümü triceps kası üzerinden; uyluk ölçümü quadriceps femoris kası üzerinden dikey olarak yapıldı. İki ölçüm arasında $\% 5^{\prime}$ den fazla fark bulunması durumunda ölçüm tekrarlandı. ${ }^{11}$

Tablo 1. Kasari FİT Skoru

\begin{tabular}{|c|c|}
\hline \multirow{4}{*}{$\begin{array}{l}\text { SIKLIK } \\
\text { (Frequency) }\end{array}$} & 5: Haftada $>=6$ defa (her gün) \\
\hline & 4: Haftada 3-5 defa \\
\hline & 3: Haftada 1-2 defa \\
\hline & 2: Ayda birkaç defa \\
\hline \multirow{5}{*}{$\begin{array}{l}\text { ŞİDDET } \\
\text { (Intensity) }\end{array}$} & $\begin{array}{l}\text { 5: Sürekli ağır nefes aldıracak şekilde orta düzeyde yüksek aerobik aktivite } \\
\text { ve aralıklı sportif aktiviteler (step aerobikler, hızlı yürüme, tenis/squash vb) }\end{array}$ \\
\hline & $\begin{array}{l}\text { 4: Sürekli ağır nefes aldırmayan orta düzeyde yüksek aerobik aktivite } \\
\text { ve aralıklı sportif aktiviteler (step aerobik, hızlı yürüme, tenis/squash vb) }\end{array}$ \\
\hline & 3: Orta aerobik aktiviteler (Normal bisiklet, jogging, vb) \\
\hline & $\begin{array}{l}\text { 2: Düşük-orta aerobikler ve sportif aktiviteler (eğlence amaçlı voleybol, } \\
\text { orta hızda yürüme) }\end{array}$ \\
\hline & 1: Hafif aerobik egzersizler (normal hızda yürüme, örn; golf yürüyüşü) \\
\hline \multirow{4}{*}{$\begin{array}{l}\text { SÜRE } \\
\text { (Time) }\end{array}$} & 4: > $30 \mathrm{dk}$. \\
\hline & 3: $20-30 \mathrm{dk}$. \\
\hline & 2: $10-20 \mathrm{dk}$. \\
\hline & 1: $<10 \mathrm{dk}$. \\
\hline \multicolumn{2}{|c|}{ F.I.T. Skoru $=($ F $) \times(I) \times(T)$} \\
\hline
\end{tabular}


Skinfold (S) ölçümlerinden vücut yağ yüzdesinin (\%VY) hesaplanmas1 ${ }^{12,13}$

1. Basamak: Skinfold ölçümlerinin toplamı alındı.

$\mathrm{S}_{3}($ Erkek$/$ Kadın $)=\mathrm{Sf}($ triceps + abdomen + uyluk $)$

2. Basamak: Cinsiyete göre geliştirilmiş formüllerle vücut yoğunluğu (Body Density-BD) bulundu.

Erkekler için: $\quad \mathrm{BD}=1.109-\left(0.8267 * \mathrm{~S}_{3}-1.6 * \mathrm{~S}_{3}{ }^{2} / 1000+0.25740 *\right.$ Yaş $) / 1000$

Kadınlar için: $\mathrm{BD}=1.099-\left(0.9929 * \mathrm{~S}_{3}-2.30 * \mathrm{~S}_{3}{ }^{2} / 1000+0.13920 *\right.$ Yaş $) / 1000$

3. Basamak: "Siri denklemi” kullanılarak VY\%'si hesapland1.

$\mathrm{VY} \%=100 \times(4.95 / \mathrm{BD}-4.5)$

Cinsiyete göre yapılan VYO değerlendirmesinde

Kritik (zayıf) $\rightarrow \mathrm{E} / \mathrm{K}=<14 /<21$

Optimal $\rightarrow \mathrm{E} / \mathrm{K}=14-18 / 21-25$

Yağlı $\rightarrow \mathrm{E} / \mathrm{K}=18-25 / 25-32$

Şişman $\quad \rightarrow \mathrm{E} / \mathrm{K}=>25 />32$ olarak

kabul edildi.

\section{İstatistiksel analiz}

Veriler SPSS 15.0 istatistik programıla (SPSS Inc., Chicago, IL, USA) değerlendirildi. Verilerin normal dağılıma uygunluğu Kolmogorov Smirnov testiyle yapıldı. İstatistiksel analizlerde yüzde dağılım oranları, Mann-Whitney $U$ ve Spearman korelasyon analizi kullanıldı. Ölçümle belirtilen değişkenler ortalama \pm standart sapma $(\mathrm{x} \pm \mathrm{ss})$; sayımla belirtilen değişkenler yüzde olarak ifade edildi. Anlamlılık düzeyi $\mathrm{p}<0.05$ olarak alınd.

\section{Bulgular}

Çalışmamızda 47 kız, 15 erkek olmak üzere toplam 62 üniversite öğrencisi yer ald1. Erkek öğrencilerin BKİ değerleri $\left(24,92 \pm 3,15 \mathrm{~kg} / \mathrm{m}^{2}\right) \quad \mathrm{k1z}$ öğrencilerden $\left(21,23 \pm 3,18 \mathrm{~kg} / \mathrm{m}^{2}\right)$ daha yüksek olarak bulundu $(\mathrm{p}=0,004)$. Tüm öğrencilerden \%65'i BKI'ne göre normal, \%15'i zayıf, $\% 18$ 'i fazla kilolu ve \%2'si obez olarak

yorumland1. Öğrencilerin fiziksel özelliklerine Tablo 2'de yer verildi.

K1z öğrencilerin VYO değerleri $(\% 22,74 \pm 6,93) \quad$ erkek öğrencilerden $(\% 16,60 \pm 5,46)$ yüksekti $(p=0,003)$. Fakat bu değerler kadın ve erkek için farklılık gösterdiğinden kendi içerisinde normal olarak kabul edildi. Kız öğrencilerin \%63'ü normal, \%21'i yağl1, \%14'ü kritik (zayıf), \%2'si çok yağlı olarak yorumlanırken, erkek öğrencilerin \%68'i normal, \%13'ü yağl1, \%13'ü çok yağlı olarak yorumland.

K1z öğrencilerin ortalama FIT skoru ile $(26,53 \pm 19,73)$ erkek öğrencilerin $(27 \pm 18,55)$ FIT skoru ortalamaları arasinda istatistiksel anlamlı fark saptanmadı $(\mathrm{p}=0,936)$. Öğrencilerin FIT skoru ortalamasına bakıldığında \%83'ü sedanter, $\% 10$ 'u iyi, \%7'si normal olarak değerlendirildi. FIT skoru çok iyi çıkan öğrenciye rastlanmadi. FIT skoru sonuçlarına göre kıların \%53,2'si erkeklerin \%46,7'si sedanter; kızların $\% 25,6$ 's1 erkeklerin \%26,7'si zayıf derecede fiziksel aktivite seviyesine sahipti. Normal ve iyi düzey fiziksel aktivite derecesi kızlarda \%10,6 erkeklerde $\% 13,3$ olarak saptand1. Hem kızlar hem de erkeklerde fiziksel aktivite derecesi çok iyi olan bir öğrenci gözlenmedi (Tablo 3). 
Tablo 2. Katılımcıların fiziksel özellikleri

\begin{tabular}{|c|c|c|c|c|}
\hline & $\mathrm{K} \mathbf{\prime z}(\mathrm{n}=47)$ & Erkek $(n=15)$ & $\mathbf{p}$ & Genel $(n=62)$ \\
\hline Yaş (yıl) & $21,01 \pm 0,93$ & $21,89 \pm 2,02$ & 0,892 & $21,72 \pm 1,33$ \\
\hline Boy (cm) & $166 \pm 0,05$ & $179 \pm 0,07$ & 0,001 & $169 \pm 0,08$ \\
\hline Vücut Ağırlığı (kg) & $58,13 \pm 8,5$ & $80,53 \pm 11,07$ & 0,001 & $63,55 \pm 13,27$ \\
\hline Beden Kütle İndeksi $\left(\mathrm{kg} / \mathrm{m}^{2}\right)$ & $21,23 \pm 3,18$ & $24,92 \pm 3,15$ & 0,004 & $22,14 \pm 3,52$ \\
\hline$\leq 18,5(\%)$ & $\% 21,2$ & - & 0,000 & $\% 15$ \\
\hline $18,6-24,9(\%)$ & $\% 63,8$ & $\% 53,3$ & 0,011 & $\% 65$ \\
\hline $25.0-29.9(\%)$ & $\% 15$ & $\% 40$ & 0,003 & $\% 18$ \\
\hline$\geq 30.0(\%)$ & - & $\% 6,7$ & 0,000 & $\% 2$ \\
\hline
\end{tabular}

Tablo 3. Katılımcıların vücut kompozisyonu ve FIT düzeyleri

\begin{tabular}{|c|c|c|c|}
\hline & $\operatorname{Kiz}(n=47)$ & Erkek $(n=15)$ & $\mathbf{p}$ \\
\hline FIT & $26,53 \pm 19,73$ & $27 \pm 18,55$ & \\
\hline Sedanter $(\%)$ & $\% 53,2$ & $\% 46,7$ & \\
\hline Zayıf (\%) & $\% 25,6$ & $\% 26,7$ & 0,936 \\
\hline Normal (\%) & $\% 10,6$ & $\% 13,3$ & \\
\hline İyi (\%) & $\% 10,6$ & $\% 13,3$ & \\
\hline Çok İyi (\%) & - & - & \\
\hline İdeal Yağ oranı (\%) & $55,77 \pm 7,11$ & $76,30 \pm 7,03$ & 0,001 \\
\hline Fazla Kilo Yüzdesi (\%) & $0,05 \pm 0,12$ & $0,06 \pm 0,11$ & $\mathbf{0 , 8 0 4}$ \\
\hline Vücut Yağ Oranı (\%) & $22,74 \pm 6,93$ & $16,60 \pm 5,46$ & \\
\hline Kritik & $\% 14$ & $\% 6$ & \\
\hline Optimal & $\% 63$ & $\% 68$ & $\mathbf{0 , 0 0 3}$ \\
\hline Yağlı & $\% 21$ & $\% 13$ & \\
\hline Şişman & $\% 2$ & $\% 13$ & \\
\hline
\end{tabular}

Cinsiyete göre yapılan istatistiksel analizlerde kız ögrencilerde ideal yağ oranı

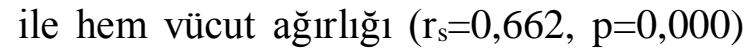
hem de BKİ $\left(r_{s}=0,481, p=0,001\right)$ arasinda pozitif yönde ilişki vardı.

Kizlarda fazla kilo yüzdesi ile VYO $\left(\mathrm{r}_{\mathrm{s}}=0,626 \quad \mathrm{p}=0,000\right), \quad$ BKI $\quad\left(\mathrm{r}_{\mathrm{s}}=0,538\right.$, $\mathrm{p}=0,000)$ ve ayrıca vücut ağırlığının $\left(r_{s}=0,472, p=0,001\right)$ pozitif yönde ilişkili olduğu da görüldü.

Erkek öğrencilerde ise ideal yağ oranı ile boy $\left(\mathrm{r}_{\mathrm{s}}=0,776, \mathrm{p}=0,001\right)$ ve $\mathrm{BKI}\left(\mathrm{r}_{\mathrm{s}}=0,520\right.$, $\mathrm{p}=0,047)$ arasında pozitif yönde ilişki bulundu.

Genel değerlendirme bazında FIT Skoru ve BKİ arasında anlamlı ilişki saptanmadi $(p>0,05)$ (Şekil 1). Ancak FIT skorunun erkeklerde vücut ağırlığ1 $\left(\mathrm{r}_{\mathrm{s}}=0,592, \quad \mathrm{p}=0,02\right), \quad \mathrm{BKI} \quad\left(\mathrm{r}_{\mathrm{s}}=0,662\right.$, $\mathrm{p}=0,007)$, VYO $\left(\mathrm{r}_{\mathrm{s}}=0,602, \mathrm{p}=0,018\right)$, ideal yağ oran1 $\left(\mathrm{r}_{\mathrm{s}}=0,544, \mathrm{p}=0,036\right)$ ve fazla kilo yüzdesi $\left(\mathrm{r}_{\mathrm{s}}=0,560, \quad \mathrm{p}=0,03\right)$ ile pozitif yönde ilişkili olduğu saptandı (Şekil 2) 


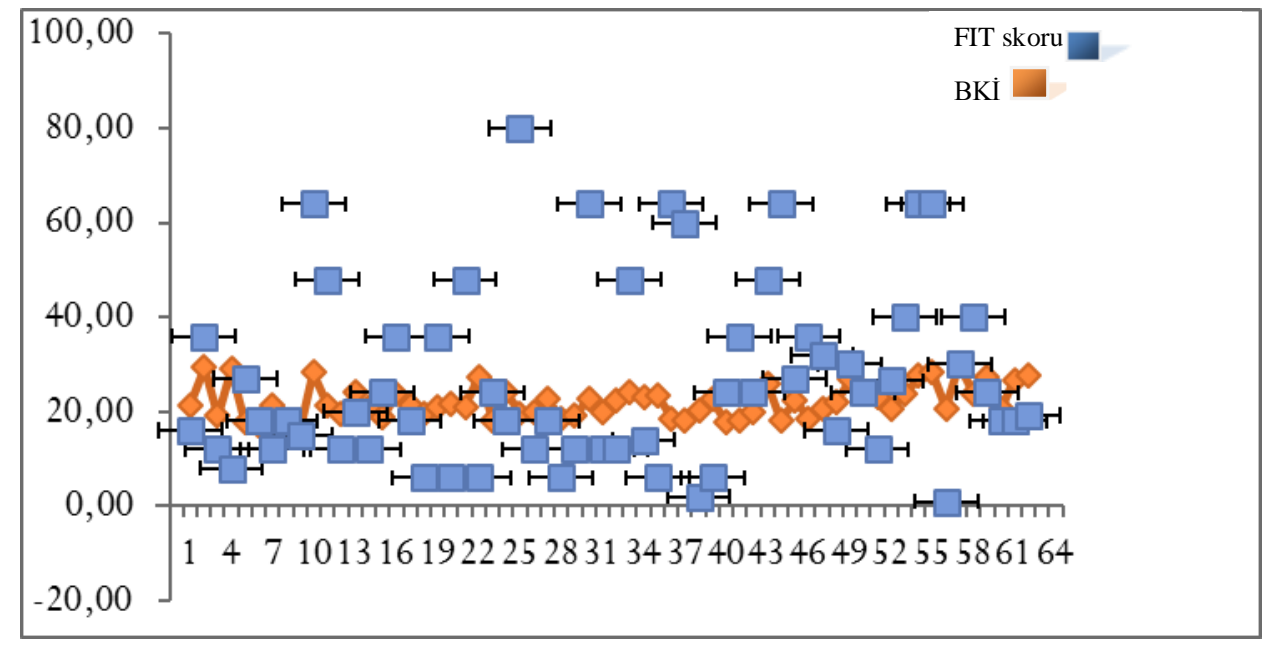

Şekil 1. Katılımcıların ortalama BKİ ve FIT skorları arasındaki ilişki

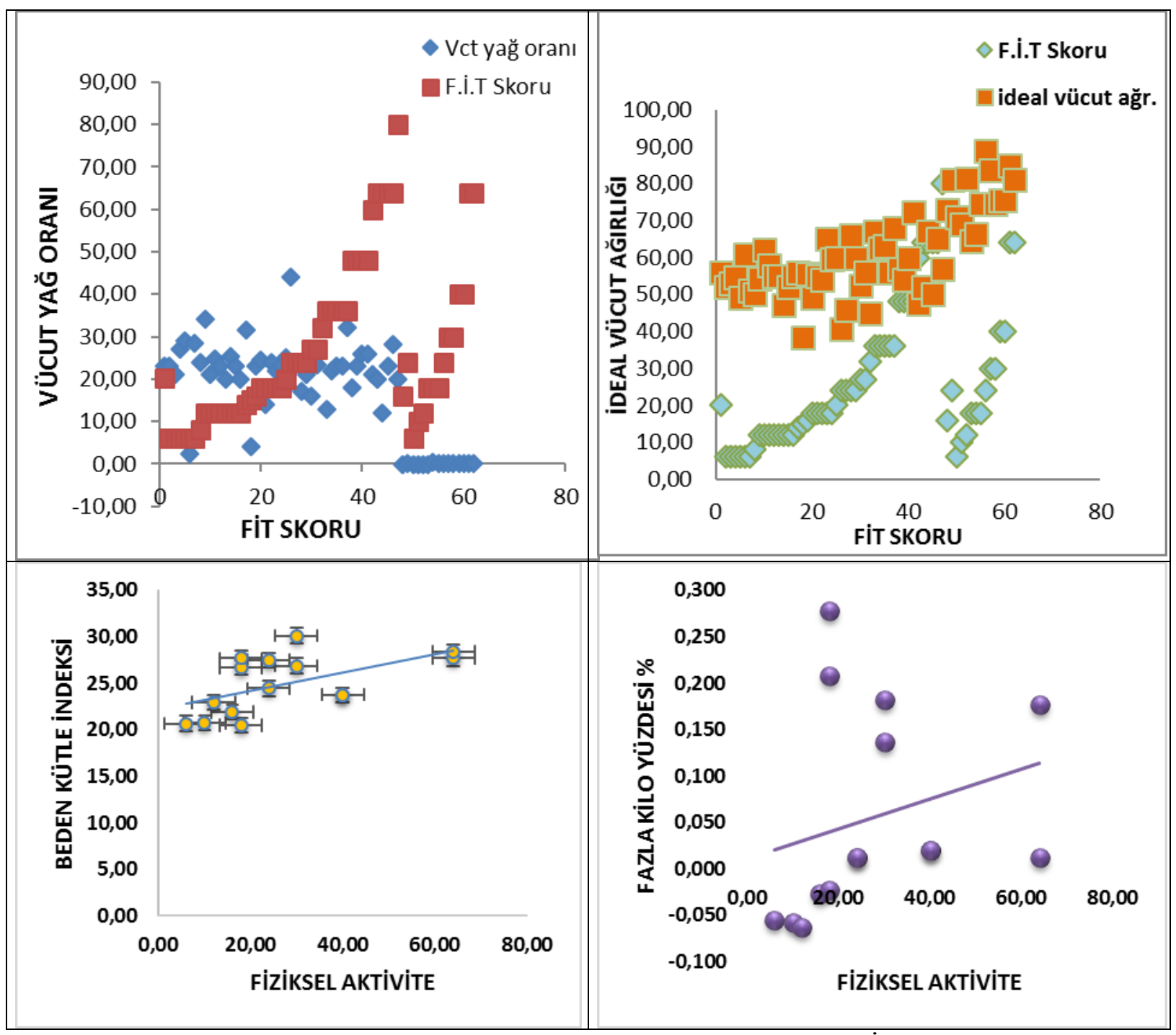

Şekil 2. Erkek katılımcılarda FA ile VYO, ideal vücut ağırlığı, BKİ ve fazla kilo yüzdesi arasındaki ilişki 


\section{Tartışma}

Sağlık Bakanlığı'nca yürütülen “Türkiye Kronik Hastalıklar ve Risk Faktörleri Siklığı" çalışmasi1 ${ }^{15}$ sonuçlarına göre ülkemizde 15-24 yaş arası erkeklerin $\% 22,1$ 'i; kızların ise \%19,9'u fazla kilolu ve şişman olarak değerlendirilmiştir. Sağlık bakanlığı sonuçlarının daha geniş yaş aralığını kapsamasının sonuçların farklılığında etkili olduğu düşüncesindeyiz. Zira aynı çalışmanın cinsiyete göre yapılan analizlerinde fazla kilolu ve obez bireylerin oranının 15-24 yaş aralığında minimum iken 45 yaş sonrasında maksimum değerlerine ulaştığı görülmektedir. $\mathrm{Bu}$ durum yaş artışı ile BKİ artışının paralel olarak ilerlediğini düşündürmektedir.

Teo ve ark. ${ }^{21}$ adölesan erkeklerde vücut yă̆ yapısı gelişiminin kızlara göre daha farklı olduğunu bu nedenle fiziksel aktivite düzeyinin kızlardan yüksek olduğunu ifade etmiştir. Buna ek olarak adölesan erkeklerin vücut ağırlığı, boy, bel çevresi ve bel kalça oranlarının da beklendiği gibi kızlardan daha yüksek olduğunu; kızlarda ise bizimde çalışmamızda saptadığımız gibi toplam vücut yağ yüzdesinin erkeklerden daha yüksek olduğunu bildirmişlerdir. Ayrıca FA düzeyi ile alt ekstremite yağ miktarı arasında negatif yönde ilişki olduğunu bildirmişlerdir. Çalışmamızda Teo ve ark benzer olarak FA düzeyi ile BKİ, vücut yağ oranı, ideal yă oranı ve fazla kilo yüzdesi arasında negatif yönde anlamlı ilişki saptadık.

Fiziksel aktivite düzeyi ile vücut kompozisyonu ilişkisini araştırmak için yaptığımız analizler doğrultusunda özellikle erkeklerde FA ile vücut yağ oran1, ideal yağ oranı ve fazla kilo yüzdesi ile ilgili saptadığımız bulgular Jiménez-Pavón ve ark.'nın ${ }^{22}$ da ifade ettiği fiziksel aktivite ile yağlanma arasındaki negatif yönlü ilişki olduğu sonuçlarını desteklemektedir.

\section{Sonuç}

Kronik hastalıkların alt yapısını hazırlayan iki majör risk faktörü olan fiziksel inaktivite ve obezite oranları toplumun her kesiminde artmaya devam etmektir. 20-23 yaş arası üniversite gençlerini değerlendirdiğimiz pilot çalışmamız kapsamında gençlerin büyük çoğunluğunun sedanter veya fiziksel aktivite katılımlarının düşük seviyelerde oluşu ve özellikle fazla kilolu birey insidansındaki artış korkutucu boyutlardadır. $\mathrm{Bu}$ durum toplumun diğer kesimlerine ek olarak üniversite öğrencilerinde de fiziksel aktiviteyi teşvik edici çalışmaların gerekliliğini ortaya koymaktadır.

\section{Yazarlar Katkısı}

Literatür araştırması, çalışmanın tasarımı: AY, FKM, DT

Verilerin toplanması: AY, FKM

Verilerin analizi, raporlama ve yazım: AY, DT

\section{Kaynaklar}

1. World Health Organization. Global action plan for the prevention and control of noncommunicable diseases 2013-2020 [updated 2013; cited 2015 July 14] Available from: http://www.who.int/entity/nmh/publicat ions/ncd-action-plan/en/ - 29k

2. Baltacı G, Irmak H, Kesici C, Çelikcan E, Çakır B. Fiziksel aktivite bilgi serisi. 1 inci Baskı. Ankara, Sağlık Bakanlığ 1 Yayın1, 2008. [Güncellenme tarihi: Şubat 2008; Erişim tarihi: Mayıs 2015] Erişim adresi: http://www.eskisehir.gov.tr/sarici/sagli k/fiziksel-aktivite-serisi/E-A4FIZIKSEL-AKTIVITE-BILGISERISI-TUMU.pdf

3. Boyce WR, Boone EL, Cioci BW, Lee AH. Physical activity, weight gain and occupational health call centre employees. Occup Med, 2008; 58:23844.

4. Heyward VH. Advanced Fitness Assessment and Exercise Prescription. 
5th ed. Illinois: Human Kinetics, 2006. p.1-5.

5. Barbosa-Silva MC, Barros AJ, Post CL, Waitzberg DL, Heymsfield SB. Can bioelectrical impedance analysis identify malnutrition in preoperative nutrition assessment? Nutrition 2003;19:422-426.

6. Daniels SR, Morrison JA, Sprecher DL, Khoury P, Kimball TR. Association of body fat distribution and cardiovascular risk factors in children and adolescents. Circulation 1999;99:541-545.

7. Erselcan T, Candan F, Saruhan S, Ayca T. Comparison of body composition analysis methods in clinical routine. Ann Nutr Metab 2000;44:243-248.

8. Gutin B, Manos T, Strong W. Defining Health and Fitness: First Step Toward Establishing Childrens Fitness Standarts. Res Q Exerc Sport 1992;63(2):128-132.

9. Vanhees L, Lefevre J, Philippaerts R, Martens M, Huygens W, Troosters T, et al. How to assess physical activity? How to assess physical fitness? Eur J Cardiovasc Prev Rehabil 2005;12:10214.

10. Kasari D. Effects of exercise and fitness on serum lipids in college women [Master Thesis]. University of Montana, Montana, 1976.

11. Sarıtaş N, Özkarafaki İ, Pepe O, Büyükipekçi S. Üniversiteli erkek ögrencilerin vücut yağ yüzdelerinin üç farklı yöntemle değerlendirilmesi [Evaluation of Body Fat Percentage of Male University Students According to Three Different Methods]. Sağlik Bilimleri Dergisi [Journal of Health Sciences]. 2011;20(2):107-115.

12. MacIntyre NR. Muscle dysfunction associated with chronic obstructive pulmonary disease. Respir Care 2006;51:840-8.

13. Wood LG, Fitzgerald DA, Gibson PG, Cooper DM, Collins CE, Garg ML. Oxidative stress in cystic fi brosis: dietary and metabolic factors. J Am Coll Nutr 2001;20:157-65.

14. T.C. Sağlık Bakanlığı, Türkiye Fiziksel Aktivite Rehberi 2014. Ankara: Kuban Matbaacılık Yayıncılık. Sağlık Bakanlığ1 Yayın No: 940. [Güncellenme tarihi:2014; Erişim tarihi: Mayıs 2015] Erişim adresi: http://beslenme.gov.tr/content/files/basi n_materyal/Fiziksel_aktivite_rehberi/fa rehberi_tr.pdf

15. T.C. Sağlık Bakanlığı, Türkiye Kronik Hastalıklar ve Risk Faktörleri Siklığ 1 Çalışması 2013. Ankara: Anıl Matbaa Ltd. Şti. Sağlık Bakanlığı Yayın No: 909. [Güncellenme tarihi:2013; Erişim tarihi: Mayıs 2015] Erişim adresi: http://sbu.saglik.gov.tr/Ekutuphane/kita plar/khrfat.pdf

16. World Health Organization. Global Recommendations on Physical Activity for Health. 2010. [updated 2010; cited 2015 July 14] Available from: http://www.who.int/entity/dietphysicala ctivity/publications/9789241599979/en / - 30k

17. Gökçay G, Furman A, Neyzi O. Updated growth curves for Turkish children aged 15 days to 60 months. Child Care Health Dev. 2008 Jul; 34(4):454-63.

18. Neyzi O, Günöz H, Furman A, Bundak R, Gökcay G, Darendeliler F ve ark. Türk çocuklarında vücut ağırlığ uzunluğu, baş çevresi ve vücut kitle indeksi referans değerleri [Weight, height, head circumference and body mass index references for Turkish children]. Çocuk Sağlığı ve Hastalıkları Dergisi [J of Child Health and Dis] 2008:51-14.

19. Savcı S, Öztürk M, Arıkan H, İnce Dİ, Tokgözoğlu L. Üniversite öğrencilerinin fiziksel aktivite düzeyleri [Physical activity levels of university students]. Türk Kardiyol Dern Arşivi [Arch Turk Soc Cardiol] 2006;34(3):166-172.

20. Şanlıer N. Gençlerde Biyokimyasal Bulgular, Antropometrik Ölçümler, 
Vücut Bileşimi, Beslenme ve Fiziksel Aktivite Durumlarının Değerlendirilmesi [Biochemical Findings among the Youth, Anthropometrical Measurements, Body Composition, Evaluation of Nutritional and Physical Activity Status]. GÜ, Gazi Eğitim Fakültesi Dergisi [GU, Journal of Gazi Educational Faculty], 2005;25(3):47-73.

21. Teo PS, Nurul-Fadhilah A, Aziz ME, Hills AP, Foo LH. Lifestyle practices and obesity in Malaysian adolescents. Int J Environ Res Public Health. 2014 May 30;11(6):5828-38.

22. Jiménez-Pavón D, Kelly J, Reilly JJ. Associations between objectively measured habitual physical activity and adiposity in children and adolescents: Systematic review. Int J Pediatr Obes. 2010;5(1):3-18. 